\title{
Perancangan Sistem Pengaman Pintu Rumah menggunakan Sidik Jari berbasis Arduino
}

Misbah Abroruddin', Fadil Ramadhan ${ }^{2}$, Ahmad Roihan ${ }^{3}$

e-mail: 1'misbah.abroruddin@raharja.info, ${ }^{2}$ fadil.ramadhan@raharja.info, ${ }^{3}$ ahmad.roihan@raharja.info

1,2,3 Sistem Komputer Universitas Raharja

Abstract-Development of information and communication technology needed in door security systems. Based on this innovation, an analysis or research is needed to propose a door security system using fingerprints as authentication authority. Every family member of the homeowner must carry out a fingerprint sensor scanning process in order to open it. Meanwhile, to open the door from inside the house, the homeowner only needs to open the sensor to open the door. Based on the testing that has been done, it can be concluded that the system or tool can be used as a security for the door of the house by using a fingerprint with an average time of reading the fingerprint sensor for 1.4 seconds.

\section{Keywords—-fingerprint sensor, solenoid, arduino}

Intisari-Perkembangan teknologi informasi dan komunikasi dibutuhkan terutama dalam sistem pengaman pintu. Berdasarkan inovasi tersebut, maka dibutuhkan analisa atau penelitian untuk merancang sebuah sistem keamanan pintu dengan menggunakan sidik jari sebagai autentikasi utamanya. Setiap anggota keluarga pemilik rumah harus melakukan proses scan sidik jarinya di sensor fingerprint, agar dapat membuka pintu. Sedangkan untuk membuka pintu dari dalam rumah, pemilik rumah hanya perlu menyentuh sensor sentuh yang ada untuk membuka pintu. Berdasarkan pengujian yang telah dilakukan, maka dapat disimpulkan bahwa sistem atau alat ini dapat digunakan sebagai pengaman pintu rumah dengan menggunakan sidik jari dengan waktu rata-rata pembacaan sensor fingerprint selama 1,4 detik.

Kata kunci-Sensor fingerprint, Solenoid, Arduino.

\section{Pendahuluan}

Semakin pesatnya perkembangan teknologi informasi di era sekarang, menghasilkan berbagai macam teknologi, mulai dari teknologi baru, hingga teknologi yang merupakan dari pengembangan dari teknologi sebelumnya. Perkembangan teknologi untuk sistem keamanan juga sangat diperlukan, khususnya untuk sistem keamanan pada pintu rumah yang bersifat pribadi.

Sudah banyak opsi untuk sistem pengamanan pintu. Mulai dari sistem yang konvensional, sampai sistem yang lebih modern seperti menggunakan RFID (Radio Frequency Identification). Dalam penggunaannya, kedua sistem tersebut memiliki kelemahan. Salah satu contoh kelemahannya yaitu human error. Dalam sistem konvensional yang menggunakan gembok[1], bisa saja kunci dari gembok tersebut hilang. Begitupun juga dengan sistem yang modern yang menggunakan RFID, bisa saja hilang kartu yang digunakan untuk membuka pintu. Untuk itu, dalam sistem pengaman pintu perlu ditingkatkan, agar kelemahan human error yang ada pada contoh sistem sebelumnya dapat diminimalisir.

Salah satu peningkatan dari sistem pengaman pintu yaitu, dengan menggunakan otentikasi biometrik sidik jari. Sistem biometrik sidik jari merupakan salah satu sistem pengaman yang paling banyak digunakan saat ini. Sistem biometrik sidik jari memiliki kelebihan diantaranya tidak dapat hilang, tidak dapat lupa, dan tidak mudah untuk dipalsukan. Keberadaannya yang melekat pada manusia, sidik jari manusia yang berbeda-beda sehingga keunikannya lebih terjamin [2].

Berdasarkan hal itu, maka penulis membuat sebuah sistem pengaman pintu menggunakan sensor sidik jari, sehingga pintu hanya dapat terbuka menggunakan sidik jari yang telah didaftarkan dan juga meningkatkan keamanan.

\section{II.Metode Penelitian}

Tujuan penelitian ini adalah untuk membuat sebuah alat pengaman pintu menggunakan sidik jari yang berbasis arduino untuk mengamankan pintu rumah. Pada penelitian ini kami menggunakan metode eksperimen atau uji coba. Eksperimen yang dilakukan yaitu pada rangkaian perangkat keras dan perangkat lunak. Secara umum blok diagram sistem dapat dilihat pada Gambar 1 


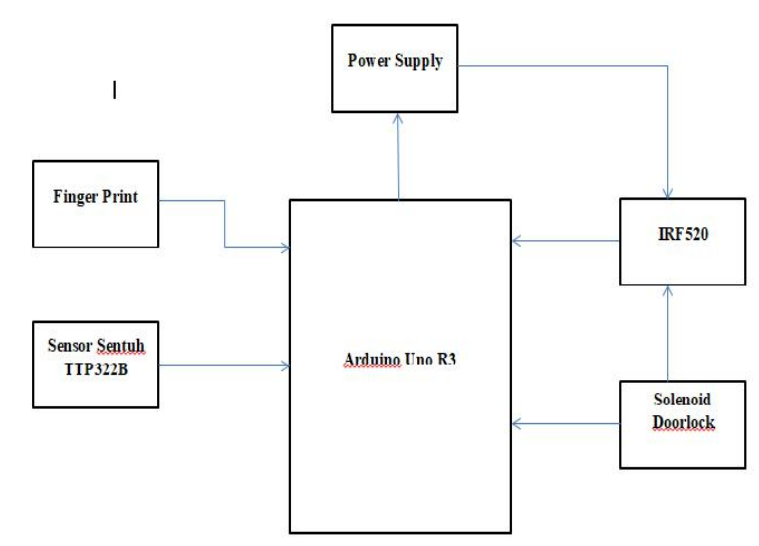

Gbr 1. Blok diagram Perancangan Sistem Pengaman Pintu

Adapun penjelasan dari setiap blok diagram tersebut adalah sebagai berikut:

1.Sensor Fingerprint

Sensor Fingerprint sebagai input utama dari sistem, sensor ini berfungsi untuk membaca sidik jari dari user yang sebelumnya sudah didaftarkan untuk membuka pintu dari dalam rumah.

2.Sensor sentuh

Sensor sentuh berfungsi pengganti sensor sidik jari sebagai input dari sistem jika ingin membuka pintu dari dalam rumah.

\section{Arduino}

Arduino berfungsi sebagai pengendali sistem utama dari sistem.

4.IRF 520

MOSFET IRF520 berfungsi sebagai switch untuk solenoid door lock.

5.Solenoide Door Lock

Solenoide Door Lock berfungsi sebagai pengunci pintu secara elektronik, dimana alat ini sebagai perangkat output utama dalam sistem ini..

Adapun skema dari sistem yang akan direncanakan seperti pada Gambar 2.

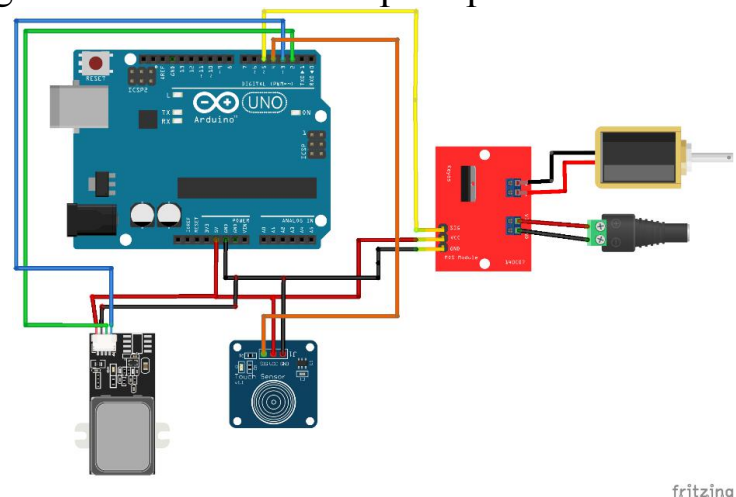

Gbr 2. Skema Sistem Pengaman Pintu

Penjelasan komponen-komponen utama yang digunakan pada sistem pengaman pintu ini adalah sebagai berikut:

\section{A. Sensor Fingerprint AS608}

Modul fingerprint yang digunakan dalam sistem adalah AS608 yang dibuat oleh sebuah perusahaan teknologi china Hangzhou Company (Synochip). AS608 berbentuk modul dan tersusun atas sensor optik fingerprint, prosesor DSP dan memori flash yang mengintegrasikan algoritma pengenalan sidik jari, dan 
dapat secara efisien dan cepat mengumpulkan gambar dan mengidentifikasi sidik jari [3]. Bentuk sensor fingerprint seperti pada Gambar 3.

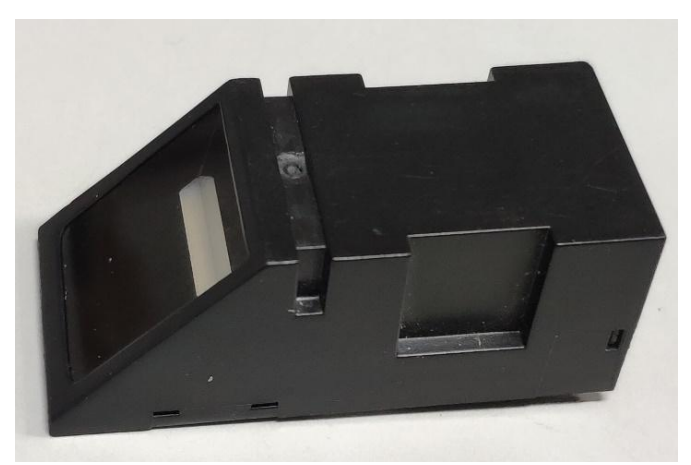

Gbr 3. Sensor fingerprint AS608

\section{B. Arduino Uno R3}

Arduino Uno R3 adalah sebuah mikrokontroler open source yang menggunakan IC Atmega328, memiliki 14 pin digital sebagai I/O, 6 masukan analog, 6 pin PWM (Pulse Width Modulation), $16 \mathrm{MHz}$ osilator kristal, port USB, jack power, ICSP Header dan tombol reset [4]. Berdasarkan memori dan peripheral lainnya ATMega328 tidak kalah dengan yang lainnya karena ukuran memori dan peripheralnya relatif sama dengan ATMega8535, ATMega32, hanya saja jumlah GPIO lebih sedikit dibandingkan lainnya [5]. Gambar Arduino dapat dilihat pada Gambar 4. Dan pin arduino yang digunakan dalam sistem ini dapat dilihat pada Tabel 1.

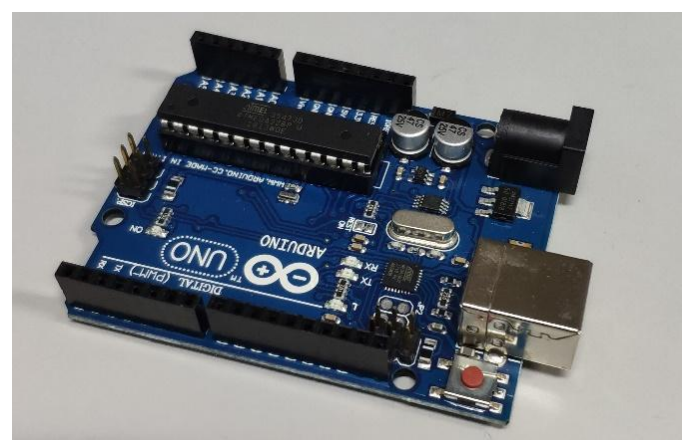

Gbr 4. Arduino Uno R3

\begin{tabular}{|l|l|}
\hline PIN & Fungsi \\
\hline 2 & TX Fingerpritnt \\
\hline 3 & RX Fingerprint \\
\hline 4 & SIG Sensor Sentuh \\
\hline 5 & SIG IRF520 \\
\hline $5 \mathrm{v}$ & Fingerprint, Sensor Sentuh, IRF520 \\
\hline GND & Fingerprint, Sensor Sentuh, IRF520 \\
\hline
\end{tabular}

Tabel 1. Pin Arduino yang digunakan

\section{Solenoide Door Lock}

Solenoide door lock merupakan suatu aktuator yang menggerakan tuas secara linier [6]. Prinsip alat ini sendiri akan aktif apabila diberikan tegangan sebesar 12 volt. Bentuk Solenoide Door Lock dapat dilihat pada Gambar 5. 


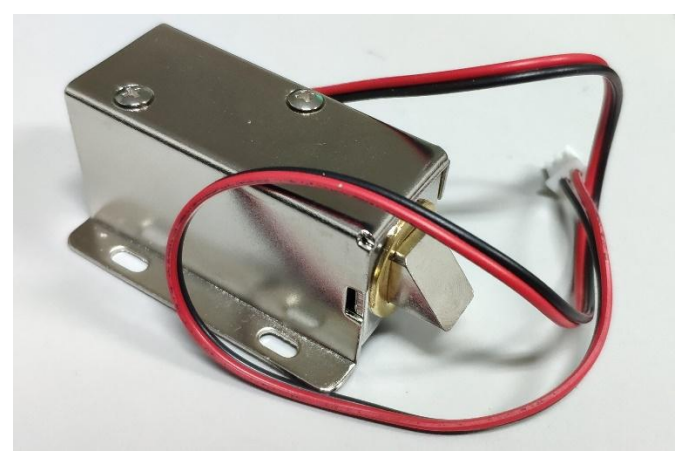

Gbr 5. Solenoide Door Lock

\section{Sensor Sentuh TTP223B}

Sensor sentuh merupakan sebuah module sensor yang berfungsi seperti tombol/ saklar [7], dan cara penggunaanya hanya perlu dengan menyentuhnya menggunakan jari. Data akan berlogika $1(H I G H)$ saat disentuh oleh jari sehingga pintu dapat terbuka dan akan berlogika 0 (Low) saat tidak disentuh. Bentuk Sensor Sentuh TTP223B seperti Gambar 6.

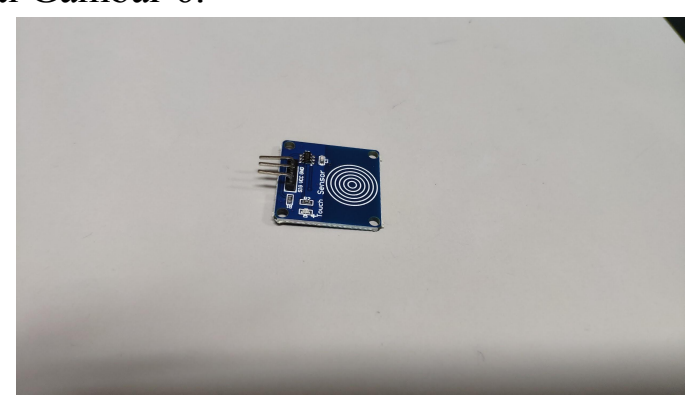

Gbr 6. Sensor Sentuh TTP223B

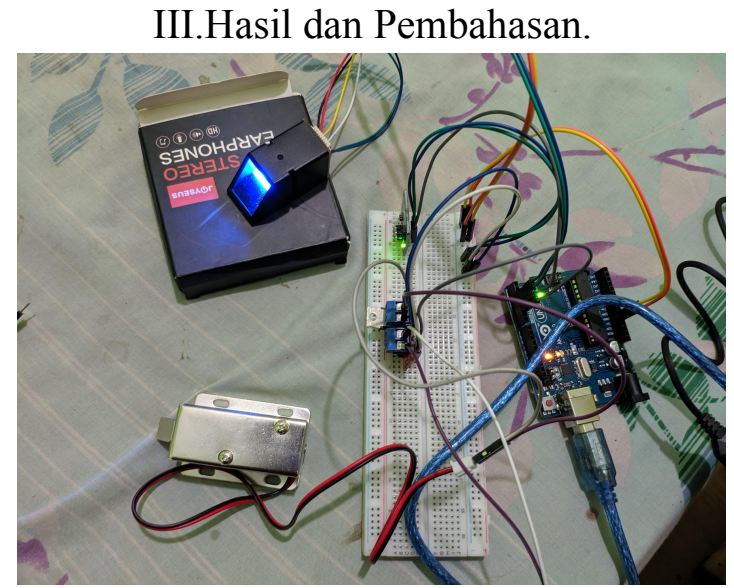

Gbr 7. Pengujian sistem

Pengujian alat atau sistem dilakukan secara keseluruhan berdasarkan kondisi sidik jari yang berbeda-beda, sehingga penulis nantinya dapat menyimpulkan bagaimana kondisi sistem terhadap sidik jari.

Langkah dalam pengujiannya yaitu, dengan cara menempelkan jari tangan pada area sensor fingerprint dengan kondisi solenoid tidak aktif. Sehingga apabila sensor fingerprint dapat mengidentifikasi atau membaca sidik jari maka sistem akan mengaktifkan solenoid.

1. Pengujian pertama 
Pada pengujian pertama, sistem dites menggunakan sidik jari ibu jari (jempol) tangan kiri penulis dan didapat bahwa sistem dapat bekerja dengan baik dengan waktu pembacaan sidik jari selama 1,2 detik untuk dapat mengaktifkan solenoid.

2. Pengujian kedua

Pada pengujian kedua, sistem dites menggunakan sidik jari telunjuk tangan kiri penulis dan didapat bahwa sistem dapat bekerja dengan baik dengan pembacaan sidik jari selama 1 detik untuk dapat mengaktifkan solenoid.

3. Pengujian ketiga

Pada pengujian ketiga, sistem dites menggunakan sidik jari tengah tangan kiri penulis dan didapat bahwa sistem dapat bekerja dengan baik dengan pembacaan sidik jari selama 3 detik untuk dapat mengaktifkan solenoid.

4. Pengujian keempat

Pada pengujian keempat, sistem dites menggunakan sidik jari ibu jari (jempol) tangan kanan penulis dan didapat bahwa sistem dapat bekerja dengan baik dengan pembacaan sidik jari selama 0,8 detik untuk dapat mengaktifkan solenoid.

5. Pengujian kelima

Pada pengujian kelima, sistem dites menggunakan sidik jari telunjuk tangan kanan penulis dan didapat bahwa sistem dapat bekerja dengan baik dengan pembacaan sidik jari selama 1 detik untuk dapat mengaktifkan solenoid.

6. Pengujian keenam

Pada pengujian keenam, sistem dites menggunakan sidik jari tengah tangan kanan penulis dan didapat bahwa sistem dapat bekerja dengan baik dengan pembacaan sidik jari selama 2 detik untuk dapat mengaktifkan solenoid.

7. Pengujian ketujuh

Pada pengujian ketujuh, sistem dites menggunakan sidik jari ibu jari (jempol) tangan kanan penulis yang dilapisi dengan selotip dan didapat bahwa sistem fingerprint tidak dapat mengidentifikasi dan membaca sidik jari. Yang artinya, sistem tidak dapat berjalan.

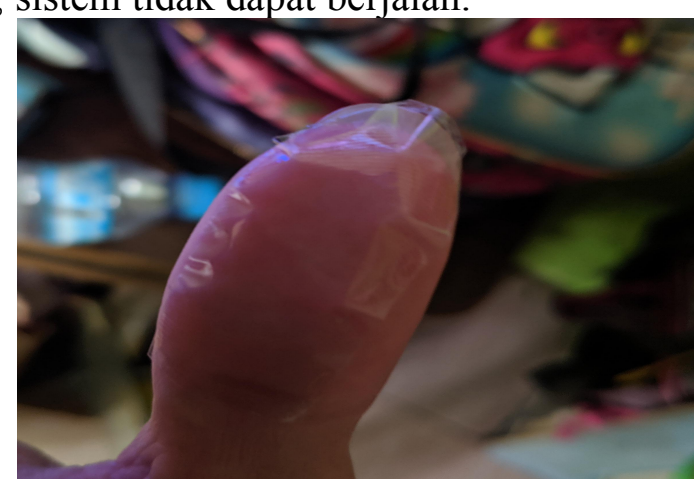

Gbr 8. Pengujian sistem menggunakan sidik jari yang dilapisi solasi

8. Pengujian kedelapan

Pada pengujian kedelapan, sistem dites menggunakan sidik jari ibu jari (jempol) tangan kanan penulis yang tercoret pulpen dan didapat bahwa sistem tetap dapat bekerja dengan baik dengan pembacaan sidik jari selama 3 detik untuk dapat mengaktifkan solenoid. 


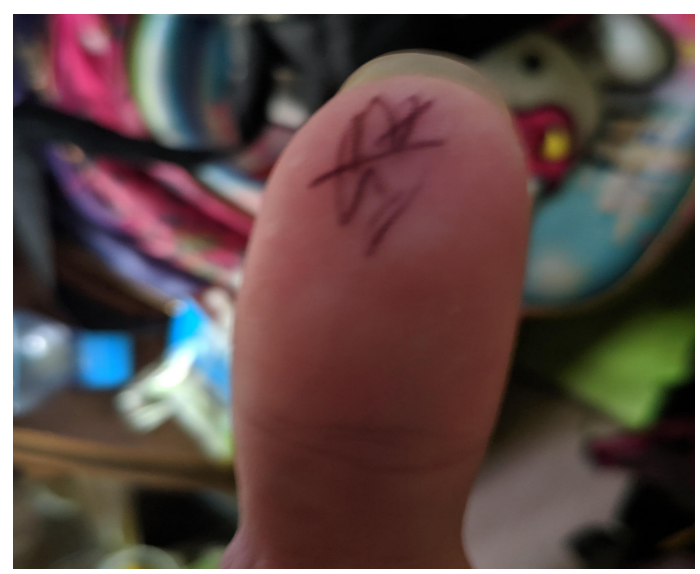

Gbr 9. Pengujian sistem menggunakan sidik jari yang tercoret pulpen

IV.Kesimpulan

Sistem dapat berjalan dengan baik sesuai dengan yang diharapkan. Sensor fingerprint yang digunakan dapat membaca sidik jari dengan cepat. Rata-rata pembacaan sidik jari yaitu 1,4 detik. Sensor fingerprint yang digunakan tetap dapat mengidentifikasi dan membaca sidik jari dengan posisi yang berbeda dan juga sidik jari yang dicoret dengan pulpen. Kemudian Listing Program pengendali solenoid door lock berdasarkan kondisi yang diterima oleh IRF520. Untuk penelitian selanjutnya, dapat dikembangkan ke arah proses monitoring yang dapat dilakukan sebagai bahan untuk pengolahan data pengguna dari sistem ini secara IoT [8].

[1] G. A. Ferry Sudarto, "PERANCANGAN SISTEM SMARTCARD SEBAGAI PENGAMAN PINTU MENGGUNAKAN RFID BERBASIS ARDUINO," CCIT, vol. 10, pp. 239-254, 2017.

[2] S. S. P. P. Anton Yudhana, "PERANCANGAN PENGAMAN PINTU BERBASIS SIDIK JARI MENGGUNAKAN METODE UML,” Jurnal Teknologi, pp. 131-138, 2018.

[3] Y. Y. Y. L. a. W. H. Haiyun Wu, "Design of Intelligent Classroom Fingerprint Attendance System," dalam International Conference on Electromechanical Control Technology and Transportation (ICECTT 2018), 2018.

[4] M. A. R. Hidayat Nur Isnianto, "Sistem Kemananan Pintu Rumah dengan Fingerprint dan Keypad berbasis Arduino," dalam Seminar Nasional Teknologi Terapan, Yogyakarta, 2015.

[5] A. Roihan, A. Permana and D. Mila, "Monitoring Kebocoran Gas Menggunakan Mikrokontroler Arduino UNO dan ESP8266 Berbasis Internet of Things," ICIT (Innovative Creative and Information Technology), vol. 2, no. 2, pp. 170-183, 2016.

[6] P. J. Hengky Yalandra, "RANCANG BANGUN PENGAMAN PINTU PERSONAL ROOM MENGGUNAKAN SENSOR SIDIK JARI BERBASIS ARDUINO," Jurnal Vokasional Teknik Elektronika dan Informatika, pp. 118-125, 2019.

[7] P. D. I. S. H. A. C. S. M. Rachman Reza A., "Prototipe Helm Cerdas berbasis Arduino Nano".

[8] A. Roihan, F. Sudarto, and T. C. Putro, "Internet of things on monitoring and control system in server area," dalam 2018 International Seminar on Application for Technology of Information and Communication. IEEE, 2018, pp. 116-120. 